\title{
INDIKASI FOTOKOAGULASI LASER PADA PASIEN RETINOPATI \\ DIABETIK DI BALAI KESEHATAN MATA PROPINSI SULAWESI \\ UTARA PERIODE JANUARI - DESEMBER 2012
}

\author{
${ }^{1}$ Renta Tappang \\ ${ }^{2}$ Harry Sumual \\ ${ }^{3}$ Laya Rares
}

\begin{abstract}
Bagian Ilmu Kesehatan Mata Fakultas Kedokteran Universitas Sam Ratulangi Manado Email: rentatappang10_010@yahoo.com
\end{abstract}

\begin{abstract}
Diabetic retinopathy is one of the vascular disorders that can occur in type 1 and 2 diabetes mellitus cases after 10-15 years. Treatment of diabetic retinopathy is based on its severity; One of the treatment is laser photocoagulation.This study aimed to find out the indication of laser photocoagulation procedure among diabetic retinopathy cases at BKMM North Sulawesi Province.This was a descriptive retrospective study using the medical records of diabetic retinopathy cases who underwent laser photocoagulation. There were 35 cases as samples who underwent laser photocoagulation during January - December 2012. The results showed that most cases were proliferative diabetic retinopathy (86,6\%). The most frequent age group was 41-60 years $(68,6 \%)$, predominantly females (60\%). Moreover, there were $80 \%$ cases who underwent one time of laser photocoagulation meanwhile the others $20 \%$ underwent more than one photocoagulation during Januari - December 2012. Conclusion: The most frequent indication of laser photocoagulation among diabetic retinopathy cases at BKMM North Sulawesi Province was proliferative diabetic retinopathy.
\end{abstract}

Keywords:indication of laser photocoagulation, retinopathy

Abstrak: Retinopati diabetik adalah suatu kelainan vaskular yang terjadi pada kasus diabetes melitus tipe 1 dan 2 setelah 10 - 15 tahun. Penatalaksanaan retinopati diabetik dibuat berdasarkan pada tingkat kelainan penyakitnya; salah satu cara ialah dengan menggunakan terapi fotokoagulasi laser. Penelitian ini bertujuan untuk mengetahui indikasi fotokoagulasi laser pada kasus retinopati diabetik di Balai Kesehatan Mata Masyarakat (BKMM) Propinsi Sulawesi Utara. Metode penelitian ini deskriptif retrospektif dengan menggunakan catatan rekam medik kasus retinopati diabetik yang telah dilakukan fotokoagulasi laser. Sampel berjumlah 35 kasus retinopati diabetik yang menjalani fotokoagulasi laser pada periode Januari - Desember 2012 dengan presentase terbanyak retinopati diabetik proliferatif (88,6\%). Kelompok usia tersering 41-60 tahun (68,6\%), sedangkan jenis kelamin didominasi oleh perempuan (60\%). Kasus yang terbanyak (80\%) ialah yang menjalani hanya satu kali fotokoagulasi laser sedangkan sisanya (20\%) menjalani tindakan tersebut lebih dari satu kali. Simpulan: Pada kasus retinopati diabetik di BKMM Propinsi Sulawesi Utara indikasi tersering untuk dilakukan fotokoagulasi laser ialah retinopati diabetik proliferatif.

Kata Kunci: indikasi fotokoagulasi laser, retinopati 
Retinopati diabetic adalah suatu kelainan vaskular yang didapatkan pada penderita diabetes mellitus tipe 1 dan 2 setelah 10 - 15 tahun. Gambaran klinis awal penyakit ini adalah mikroaneurisma dan perdarahan retina. Pada keadaan yang lebih lanjut, kelainan ini dapat ditandai dengan pertumbuhan abnormal pembuluh darah retina yang disebabkan oleh iskemia retina. ${ }^{1}$ Retinopati diabetik mengenai sebagian besar pasien diabetes melitus. Retinopati nonproliferatif terdiri dari perdarahan intraretina serta preretina, eksudasi, edema, penebalan kapiler retina dan mikroaneurisma. Retinopati proliferative merupakan proses neovaskularisasi dan fibrosis pada retina dengan kecenderungan yang tinggi untuk menimbulkan kebutaan. ${ }^{2}$

Seiring dengan meningkatnya jumlah pasien diabetes melitus, meningkat pula prevalensi retinopati diabetik dan resiko kebutaan yang diakibatkannya. Survey kesehatan di Amerika Serikat dari tahun 2005 sampai 2008 yang melibatkan pasien diabetes mellitus menunjukkan 28,5\% diantaranya didiagnosis sebagai retinopati diabetic dan $4,4 \%$ dengan retinopati diabetik yang terancam buta. $^{3}$

Retinopati diabetic sering terjadi pada kelompok usia 20-60 tahun. Di Negara berkembang $12 \%$ kasus kebutaan disebabkan oleh diabetes melitus. Retinopati diabetic merupakan kasus terbanyak yang dilayani di klinik Vitreo-Retina Rumah Sakit Cipto Mangunkusumo. Retinopati diabetic menempati urutan keempat setelah katarak, glaukoma, dan degenerasi makula $(\mathrm{AMD}=$ Age-related macular degeneration) secara global. ${ }^{4}$

Penatalaksanaan retinopati diabetik dibuat berdasarkan pada tingkat kelainan penyakitnya. Salah satu cara adalah dengan menggunakan terapi fotokoagulasi laser. Fotokoagulasi laser telah memberikan hasil yang baik pada retinopati diabetik yang disertai clinically significant macular edema (CSME), neovaskularisasi pada retina dan pada penderita dengan resiko tinggi proliferative disease. Dengan fotokoagulasi laser, progesifitas retinopati diabetic dapat diturunkan secara efektif yaitu sekitar 90\%, sehingga kehilangan tajam penglihatan yang berat dapat dihindari. ${ }^{1}$
Terdapat tiga metode fotokoagulasi laser pada retinopati diabetik. Pertama adalah Scatter (panretinal) yang dapat memperlambat perkembangan serta meregresi neovaskularisasi pada diskus optikus dan permukaan retina. Kedua ,fotokoagulasi fokal yang ditujukan langsung pada kebocoran di fundus posterior retina untuk mengurangi edema makula. Ketiga adalah fotokoagulasi grid, yang ditujukan pada daerah edema yang terjadi akibat kebocoran kapiler yang difus. ${ }^{1}$

\section{METODOLOGI}

Penelitian ini adalah penelitian yang menggunakan metode deskriptif dengan pendekatan studi retrospektif. Bahan yang digunakan adalah berupa catatan medic penderita retinopati diabetik yang menjalani fotokoagulasi laser di Balai Kesehatan Mata Masyarakat (BKMM) Propinsi Sulawesi Utara selama periode Januari - Desember 2012. Penelitian dilaksanakan di Balai Kesehatan Mata Masyarakat (BKMM) Propinsi Sulawesi Utara. Penelitian ini dilakukan pada bulan November 2013- Desember 2013. Subjek penelitian adalah semua pasien retinopati diabetik yang menjalani fotokoagulasi laser di Balai Kesehatan Mata Masyarakat (BKMM) Propinsi Sulawesi Utara selama periode Januari- Desember 2012. Variabel Penelitian ialah usia, jenis kelamin, tingkat retinopati diabetik, dan berapa kali dilakukan fotokoagulasi laser.

\section{HASIL PENELITIAN}

Berdasarkan pengumpulan data yang dilakukan selama bulan November 2013 secara deskriptif retrospektif di Balai Kesehatan Mata Masyarakat (BKMM) Propinsi Sulawesi Utara periode Januari 2012 - Desember 2012 , maka didapatkan 35 penderita retinopati diabetik yang melakukan terapi fotokoagulasi laser. Hasil penelitian menunjukkan bahwa penderita retinopati diabetik yang telah melakukan fotokoagulasi laser pada kelompok umur 41 60 tahun memiliki jumlah yang paling banyak yaitu 24 penderita dengan presentase sebesar 68,6 \% (Tabel 1). 
Tabel 1. Distribusi penderita retinopati diabetik yang menjalani fotokoagulasi laser menurut kelompok umur

\begin{tabular}{ccc}
\hline Umur & Jumlah & $\begin{array}{c}\text { Persentase } \\
(\%)\end{array}$ \\
\hline $20-40$ tahun & 3 & 8,6 \\
$41-60$ tahun & 24 & 68,6 \\
$>60$ tahun & 8 & 22,9 \\
\hline Total & 35 & 100 \\
\hline
\end{tabular}

Dari data penelitian didapatkan bahwa dari 35 penderita retinopati diabetik yang difotokoagulasi laser didapatkan paling banyak penderita berjenis kelamin perempuan yaitu sebanyak 21 penderita dengan presentase sebesar $60 \%$ (Tabel 2).

Tabel 2. Distribusi penderita retinopati diabetik yang menjalani fotokoagulasi laser menurut jenis kelamin

\begin{tabular}{ccc}
\hline JenisKelamin & Jumlah & Persentase (\%) \\
\hline Laki-Laki & 14 & 40 \\
Perempuan & 21 & 60
\end{tabular}

\section{Total} 35 100

Hasil penelitian menunjukkan bahwa penderita retinopati diabetik yang termasuk dalam Retinopati Diabetik Proliferatif /Proliferative Diabetic Retinopathy (PDR) merupakan kelompok terbanyak yang difotokoagulasi laser dengan jumlah 31 penderita dengan presentase sebesar 88,6\% (Tabel 3).

Tabel 3. Distribusi penderita retinopati diabetik yang menjalani fotokoagulasi laser menurut tingkat retinopati diabetik

\begin{tabular}{ccc}
\hline $\begin{array}{c}\text { Tingkat } \\
\text { RetinopatiDiabetik }\end{array}$ & Jumlah & $\begin{array}{c}\text { Persentase } \\
(\mathbf{\%})\end{array}$ \\
\hline NPDR & 4 & 11,4 \\
PPDR & 0 & 0 \\
PDR & 31 & 88,6 \\
& & \\
\hline Total & 35 & 100 \\
\hline
\end{tabular}

Berdasarkan hasil penelitian, didapatkan bahwa dari 35 penderita retinopati diabetik yang difotokoagulasi laser didapatkan ada 28 penderita yang melakukan 1 kali fotokoagulasi laser dengan presentase sebesar $80 \%$ dan ada 7 penderita yang melakukan lebih dari 1 kali fotokoagulasi laser dengan presentase sebesar 20\% (Tabel 4).

Tabel 4. Distribusi penderita retinopati diabetik yang menjalani fotokoagulasi laser menurut jumlah dilakukan fotokoagulasi laser

\begin{tabular}{ccc}
\hline $\begin{array}{c}\text { Berapa kali } \\
\text { melakukan } \\
\text { fotokoagulasi } \\
\text { laser }\end{array}$ & $\begin{array}{c}\text { Jumlah } \\
\text { (Penderita) }\end{array}$ & $\begin{array}{c}\text { Persentase } \\
\mathbf{( \% )}\end{array}$ \\
\hline 1 kali & 28 & 80 \\
$>1 \mathrm{kali}$ & 7 & 20 \\
\hline Total & 35 & 100 \\
\hline
\end{tabular}

\section{PEMBAHASAN}

Dari hasil penelitian yang dilakukan secara deskriptif retrospektif di BalaiKesehatan Mata Masyarakat (BKMM) Propinsi Sulawesi Utara periode Januari 2012 sampai Desember 2012 terdapat 35 penderita retinopati diabetik yang telah difotokoagulasi laser.

Hasil penelitian penderita retinopati diabetik yang telah difotokoagulasi laser berdasarkan kelompok umur yaitu paling banyak pada umur 41 - 60 tahun dengan jumlah 24 penderita (68,6\%). Pada kelompok umur lebih dari 60 tahun terdapat 8 penderita (22,9\%). Sedangkan pada kelompok umur 20-40 tahun memiliki jumlah paling sedikit yaitu 3 penderita (8,6\%). Hal ini sesuai dengan penelitian yang dilakukan di Rumah Sakit Mata Cicendo Bandung periode Januari 2004 sampai Desember 2004, bahwa kelompok umur yang paling banyak dilakukan fotokoagulasi laser adalah antara 41 - 50 tahun dan $51-60$ tahun $(36,84 \%){ }^{1}$

Dari data - data yang diperoleh berdasarkan hasil penelitian penderita retinopati diabetik yang telah difotokoagulasi laser menurut jenis kelamin, didapatkan bahwa penderita dengan jenis kelamin perempuan memiliki jumlah yang paling banyak yaitu 21 penderita (60\%), sedangkan laki - laki sebanyak 14 penderita (40\%). Hal ini juga sesuai dengan penelitian yang dilakukan di Rumah Sakit Mata Cicendo Bandung, bahwa terapi fotokoagulasi laser lebih banyak dilakukan oleh penderita retinopati diabetik yang berjenis kelamin perempuan, yaitu sebanyak 24 penderita $(63,16 \%){ }^{1}$ 
Berdasarkan hasil penelitian penderita retinopati diabetik yang telah difotokoagulasi laser menurut tingkat retinopati diabetik, penderita dengan retinopati diabetik proliferatif / Proliferative Diabetic Retinopathy (PDR) adalah kelompok yang terbanyak yaitu 31 penderita (88,6\%). Sedangkan penderita dengan retinopati diabetik nonproliferatif/Non Proliferative Diabetic Retinopathy (NPDR) memiliki jumlah 4 penderita $(11,4 \%)$. Hal ini menunjukkan bahwa retinopati diabetik proliferative/Proliferative Diabetic Retinopathy merupakan penyebab tersering seseorang melakukan fotokoagulasi laser sekaligus juga merupakan komplikasi mata yang paling parah pada penderita diabetes mellitus. ${ }^{5}$

Hasil penelitian terhadap penderita retinopati diabetik yang telah difotokoagulasi laser di Balai Kesehatan Mata Masyarakat (BKMM) Propinsi Sulawesi Utara periode Januari sampai Desember 2012 menunjukkan bahwa ada 28 penderita (80\%) yang melakukan satu kali fotokoagulasi laser, dan ada 7 penderita (20\%) yang melakukanfotokoagulasi laser lebih dari satu kali.

\section{KESIMPULAN}

Dari hasil penelitian dapat disimpulkan bahwa pada kasus retinopati diabetik di BKMM Propinsi Sulawesi Utara indikasi tersering untuk dilakukan fotokoagulasi laser ialah retinopati diabetik proliferatif.

\section{SARAN}

Penderita retinopati diabetik yang telah difotokoagulasi laser sebaiknya melakukan kontrol secara teratur agar dapat diketahui apakah tajam penglihatannya membaik atau tidak.

\section{DAFTAR PUSTAKA}

1. Boesoirie SF. Keberhasilan terapi fotokoagulasi laser pada pasien retinopati diabetik di rumah sakit mata cicendo Bandung periode januari-desember 2004. http://pustaka.unpad.ac.id/wpcontent/uploads/2009/10/keberhasilan_tera pi_fotokoagulasi_laser.pdf (accessed October 12, 2013).

2. Mitchell, Kumar, Abbas, Fausto. Dasar patologis penyakit, 17 ed. Jakarta: Buku kedokteran EGC; 2009.
3. Nasution K. Deteksi dini retinopati diabetik di pelayanan primer Indonesia. J Indon Med Assoc 2011; 61(8): 307.

4. Anugrah J. Hubungan diabetes melitus dan retinopati di RSUD DR Soedarso Pontianak periode januari-desember 2010. Jurnal mahasiswa PSPD FK Universitas Tanjungpura 2013; 2(1): 6 . http://jurnal.untan.ac.id/index.php/jfk/articl e/view/3049/3027 (accessed October 12, 2013).

5. Riordan-Eva P. Retina. In: Fletcher EC, Chong NHV, Shetlar DJ, editors. Oftalmologi Umum Vaughan \& Asbury, 17 ed. Jakarta: Buku Kedokteran EGC; 2010. 